\title{
O Regime de Colaboração na Constituição e nas Legislações entre 1988 e 2020
}

\section{The Collaboration Regime in the constitution and laws between 1988 and 2020}

\author{
Renato Alexandre Oliveira Candido ${ }^{1}$
}

\begin{abstract}
Resumo
O regime de colaboração coloca a necessidade dos Estados, Distrito Federal, Municípios e União realizarem políticas educacionais em conjunto, de forma colaborativa, através de pactos que visam melhorar a oferta de educação no território nacional. Com base na análise documental, este artigo compara o Regime de Colaboração presente no Artigo 211 Constituição Federal de 1988 e nas legislações entre os anos de 1988 e 2020. Como resultado, é observado a evolução de sua interpretação pelo avanço da presença dentro das legislações ao longo destes anos, bem como a necessidade de que professores e gestores de instituições de ensino conheçam o real sentido do regime de colaboração, conhecendo as várias formas que os pactos podem ser utilizados para melhoria da educação podem ser celebrados entre os entes federados.
\end{abstract}

Palavras-chave: Regime de Colaboração; Federalismo; Política educacional

\begin{abstract}
The collaboration regime places the need for the States, Federal District, Municipalities and the Union to carry out educational policies together, in a collaborative way, through pacts that aim to improve the offer of education in the national territory. Based on the documental analysis, this article compares the Collaboration Regime present in Article 211 Federal Constitution of 1988 and in the legislations between the years 1988 and 2020. Over these years, as well as the need for teachers and managers of educational institutions to know the real meaning of the collaboration regime, knowing the various ways that pacts can be used to improve education can be celebrated between federated entities.
\end{abstract}

Keywords: Collaboration Regime; Federalism; Educational politics

\section{Introdução}

1 Professor do Instituto Federal de Educação Ciência e Tecnologia do Sul de Minas Gerais - IF Sul de Minas Orcid http://orcid.org/0000-0002-9260-4893. Email realexo@gmail.com 
A nomenclatura Regime de Colaboração surgiu na Constituição Federal de 1988 dentro do Artigo 211 para abordar a relação entre os entes federados (Estados, Distrito Federal e Municípios), na elaboração de políticas voltadas à educação. O texto constitucional de 1988 não indica, entretanto, como as políticas educacionais seriam estabelecidas nesse regime, ou sua obrigatoriedade, somente expondo a necessidade de um Regime de Colaborativo entre os entes federados, e entre estes e a União. O Termo Regime de Colaboração é diferente, conforme afirma Abrucio (2010), quando comparado com outras áreas da administração pública, como a saúde, que utilizam do termo "cooperação entre os entes federados" (BRASIL, 1988, p.01). E, esta diferenciação remete à necessidade de uma distinção na elaboração das políticas educacionais frente aos outros serviços públicos.

Este artigo, com base na análise documental, apresenta legislações federais que tratam do Regime de Colaboração entre os anos de 1996 e 2020. Nesse sentido, parte-se da Lei de Diretrizes e Bases da Educação Nacional de 1996, LDBEN 9394/96, concluindo o período da análise no ano de 2014, quando foi sancionado o Plano Nacional de Educação (PNE), Lei $n^{\circ} 13.005 / 2014$. Isso em virtude de que entre os anos de 2014 e 2020, não houve sanções de novas leis federais que abordam o Regime de Colaboração.

Com isso, são traçados comparativos na abordagem do termo Regime de Colaboração entre as legislações, destacando a importância e a forma como foi citado em cada lei federal, acenando para o entendimento da evolução de seu conceito e também, como o governo demonstrou a necessidade de políticas educacionais em Regime de Colaboração entre os entes da federação.

\section{O Regime de Colaboração na Constituição Federal de 1988 e na LDBEN 9394/96}

O Regime de Colaboração está previsto na Constituição Federal de 1988, primeiramente, no parágrafo único do Artigo 23, com vistas à concretização do parágrafo quinto do mesmo artigo:

Art. 23. É competência comum da União, dos Estados, do Distrito Federal e dos Municípios:

$[\ldots]$ 
V - proporcionar os meios de acesso à cultura, à educação, à ciência, à tecnologia, à pesquisa e à inovação;

$[\ldots]$

Parágrafo único. Leis complementares fixarão normas para a cooperação entre a União e os Estados, o Distrito Federal e os Municípios, tendo em vista o equilíbrio do desenvolvimento e do bem-estar em âmbito nacional. (BRASIL, 1988, p. 01)

Nesse sentido, o parágrafo quarto do Artigo 30, quando dispõe sobre as responsabilidades dos municípios, retoma a necessidade de políticas em Regime de Colaboração. Este Regime de Colaboração está aí implícito, quando menciona que os municípios devem manter programas de educação infantil e de ensino fundamental com a cooperação técnica e financeira da União: "VI - manter, com a cooperação técnica e financeira da União e do Estado, programas de educação infantil e de ensino fundamental;" (BRASIL, 1988, p. 01).

A partir do texto constitucional de 1988, houve um grande movimento para auxiliar os municípios no cumprimento dessa ordenação jurídica. Para atender a demanda de educação municipal e dar apoio financeiro aos programas de educacionais, os fundos governamentais tiveram grande expressão nas políticas públicas de financiamento educacional ${ }^{2}$. Esses fundos, a exemplo do Fundo de Desenvolvimento da Educação Básica - FUNDEB, são formados pela contribuição proporcional à arrecadação de cada ente federado, e redistribuição dos recursos, conforme o número de matrículas de cada sistema público educacional. Assim, entes federados com menor arrecadação recebem a mesma fração por aluno do que entes federados com maior arrecadação.

Esses fundos foram associados como políticas em Regime de Colaboração, porém,

\footnotetext{
${ }^{2}$ Sobre o conceito de Financiamento: "Financiamento é o dispêndio de recursos para determinada finalidade. $\mathrm{Na}$ execução de políticas educacionais, para resolver à demanda de ensino fundamental (por exemplo), o Estado lança e recolhe tributos e, desta receita, executa o gasto público na construção e manutenção de escolas, pagamento de salário de professores e funcionários, aquisição de equipamentos e material didático. $\mathrm{O}$ financiamento da educação compreende desde o planejamento para eleger as alternativas de atendimento, a cobrança e distribuição dos tributos controlados por um orçamento, até o gasto propriamente dito e a avaliação dos resultados" (BRASILIA, 2009, p. 43).
} 
são previstos no Artigo 60 das Disposições Constitucionais Transitórias da Constituição Federal de 1988, complementado pelo disposto no Artigo 212. Enquanto que o Regime de Colaboração é previsto claramente pelo Artigo 211, ou seja, o Regime de Colaboração e a existência de fundos estão previstos em artigos diferentes da Constituição Federal. Assim, o Artigo 211 estabelece em seu parágrafo primeiro que o Regime de Colaboração não se restringe somente à questão financeira. Porém, a função redistributiva e supletiva deve estar em Regime de Colaboração:

Art. 211. A União, os Estados, o Distrito Federal e os Municípios organizarão em regime de colaboração seus sistemas de ensino.

$\S 1^{\circ}$ A União organizará o sistema federal de ensino e o dos Territórios, financiará as instituições de ensino públicas federais e exercerá, em matéria educacional, função redistributiva e supletiva, de forma a garantir equalização de oportunidades educacionais e padrão mínimo de qualidade do ensino mediante assistência técnica e financeira aos Estados, ao Distrito Federal e aos Municípios. (BRASIL, 1988, p. 01)

O Artigo 211 da Constituição Federal de 1988 pode dar entendimento que os fundos podem ser considerados como a plena implementação do Regime de Colaboração. Porém, o mesmo artigo define a obrigação da União de fornecer assistência técnica aos entes federados e não cita a colaboração financeira entre os governos subnacionais, sem a participação da União. Se os fundos podem ser interpretados como uma política em Regime de Colaboração, cumprindo-se, parcialmente, o parágrafo primeiro do Artigo 211 da Constituição Federal de 1988, ainda fica a necessidade de cumprimento do parágrafo quarto do Artigo 211. Fica ausente a imprescindibilidade de formas de colaboração na organização dos sistemas educacionais, não abordando a questão financeira, como deixa claro o Artigo 211: “§ $4^{\circ} \mathrm{Na}$ organização de seus sistemas de ensino, a União, os Estados, o Distrito Federal e os Municípios definirão formas de colaboração, de modo a assegurar a universalização do ensino obrigatório" (BRASIL, 1988, p. 01).

Se o entendimento do parágrafo quarto do artigo 211 fosse somente sobre o financiamento para a educação, não haveria a necessidade do primeiro parágrafo do artigo 
211, nem mesmo do artigo 214 da Constituição Federal de 1988, que retoma o Regime de Colaboração e estabelece o Plano Nacional de Educação (PNE). No artigo 214, o Regime de Colaboração é retomado no sentido de articulador, sem menção à questão financeira:

Art. 214. A lei estabelecerá o plano nacional de educação, de duração decenal, com o objetivo de articular o sistema nacional de educação em regime de colaboração e definir diretrizes, objetivos, metas e estratégias de implementação para assegurar a manutenção e desenvolvimento do ensino em seus diversos níveis, etapas e modalidades por meio de ações integradas dos poderes públicos das diferentes esferas federativas que conduzam a:

I - Erradicação do analfabetismo;

II - Universalização do atendimento escolar;

III - Melhoria da qualidade do ensino;

IV - Formação para o trabalho;

V - Promoção humanística, científica e tecnológica do País.

VI - Estabelecimento de meta de aplicação de recursos públicos em educação como proporção do produto interno bruto. (BRASIL, 1988, p. 01).

A análise dos Artigos 211 e 214 leva à conclusão que o Regime de Colaboração não se restringe à cooperação financeira entre os entes federados, incluindo a criação de relações intergovernamentais de várias naturezas (financeira, de gestão, de apoio didático, entre outras) entre eles.

O artigo 214 estabelece que o Plano Nacional de Educação (PNE) deva ser uma legislação que busque a plena implantação do Regime de Colaboração entre os entes federados, fundamentando legalmente a necessidade de criação e consolidação de um arranjo que fortaleça o Regime de Colaboração.

Por sua vez, o artigo 23 da Constituição Federal de 1988, reformulado pela Emenda Constitucional $n^{0} 53$ de 2006, traz, em seu parágrafo único, a necessidade de criação de Leis complementares que fixarão as "normas para a cooperação entre a União e os Estados, o 
Distrito Federal e os Municípios, tendo em vista o equilíbrio do desenvolvimento e do bemestar em âmbito nacional" (BRASIL, 2006, p. 01). Abordado no artigo 211 como um tipo de cooperação entre os entes federados, o Regime de Colaboração na educação não foge ao estipulado no artigo 23, necessitando também de uma legislação específica que fixe as normas de sua implementação.

A Constituição Federal de 1988 traz a necessidade de uma legislação que trate do Regime de Colaboração além da questão do financiamento, abrangendo outras formas de parcerias. Porém não especifica como seriam estas parcerias, deixando para que as posteriores leis estabeleçam, não enrijecendo a legislação.

De 1988 até 1996 não houve sanção de leis federais que tratassem do Regime de Colaboração, corroborando com a falta de interpretação do termo. Segundo Werle (2009), a pouca interpretação, entendimento e empenho para a implantação do Regime de Colaboração são as razões da ausência de resultados no início dessa política. O que levou o governo reforçar a importância do Regime de Colaboração entre os entes federados, para tentar torná-lo uma institucionalidade nas esferas administrativas.

A primeira legislação educacional complementar sancionada após a promulgação da Constituição Federal de 1988 foi a Lei no 9394/1996, chamada de Lei de Diretrizes e Bases da Educação Nacional (LDBEN 9394/96). A LDBEN 9394/96 reforçou, em seu art. oitavo, a necessidade de políticas públicas para a educação que sejam em Regime de Colaboração entre os entes federados, contudo, não esclareceu como essas políticas seriam implementadas e caracterizadas. O Artigo $8^{\circ}$ continua a deixar vago o conceito de Regime de Colaboração, porém, estipula a necessidade do Governo Federal de coordená-lo:

Art. $8^{\circ}$ A União, os Estados, o Distrito Federal e os Municípios organizarão, em regime de colaboração, os respectivos sistemas de ensino.

$\S 1^{\circ}$ Caberá à União a coordenação da política nacional de educação, articulando os diferentes níveis e sistemas e exercendo função normativa, redistributiva e supletiva em relação às demais instâncias educacionais.

$\S 2^{\circ}$ Os sistemas de ensino terão liberdade de organização nos termos desta Lei. (BRASIL, 1996, p. 01). 
A análise do primeiro parágrafo do Artigo $8^{\circ}$ evidencia que o Regime de Colaboração não se restringe às questões de financiamento e redistribuição de recursos, e que a coordenação da política educacional é obrigatoriedade da União: “Caberá à União a coordenação da política nacional de educação, articulando os diferentes níveis e sistemas" (BRASIL, 1996, p. 01). Ao articular os diferentes níveis e sistemas educacionais, a União exerce "função normativa, redistributiva e supletiva em relação às demais instâncias educacionais" (BRASIL, 1996, p.01). Ou seja, a LDBEN 9394/1996 deixa claro que a União deve articular os níveis e sistemas educacionais e exercer função normativa, redistributiva e supletiva, dessa forma, cabendo à União a função de articular o Regime de Colaboração entre os entes federados.

Para reforçar a ideia exposta acima, a LDBEN 9394/1996 ainda traz em seu Artigo 62 a necessidade de políticas de formação de professores em Regime de Colaboração entre os entes federados. Estas políticas devem abranger, não somente a formação inicial, mas também, a formação continuada e conjuntamente de capacitação dos profissionais que já atuam no magistério, conforme fica claro quando se analisa a lei:

Art. 62. A formação de docentes para atuar na educação básica far-se-á em nível superior, em curso de licenciatura plena, admitida, como formação mínima para o exercício do magistério na educação infantil e nos cinco primeiros anos do ensino fundamental, a oferecida em nível médio, na modalidade normal.

§ 1 A União, o Distrito Federal, os Estados e os Municípios, em regime de colaboração, deverão promover a formação inicial, a continuada e a capacitação dos profissionais de magistério. (BRASIL, 1996, p. 01).

Semelhante ao Artigo 214 da Constituição Federal de 1988, o Artigo 62 da LDBEN 9394/1996 não faz menção à questão do financiamento, nem mesmo da redistribuição de recursos para formação de professores dos diversos níveis de ensino dos entes federados. $\mathrm{O}$ Artigo 62 traz a necessidade de articulação entre os entes federados, tanto vertical, ou seja, entre governos de esferas administrativas diferentes, quanto horizontal, entre governos subnacionais de mesma esfera administrava. A ocorrência conjunta de articulação vertical e 


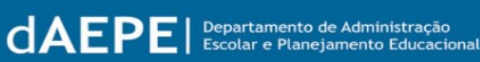

horizontal deixa claro que o Regime de Colaboração não se restringe somente à questão dos financiamentos.

Em conformidade com a Constituição Federal de 1988, a LDBEN 9394/1996 não tratou o Regime de Colaboração somente na questão do investimento, porém, também não apresentou muitas soluções para outras formas de colaboração. O único incremento está na necessidade do Regime de Colaboração na formação dos profissionais de magistério. Assim, a LDBEN 9394/1996 continuou a deixar um vácuo de entendimento para as legislações posteriores.

\section{O Regime de Colaboração no Plano Nacional de Educação (Lei no ${ }^{0}$ 10.172/2001 e Lei no}

\subsection{5/2014 ) e seus desdobramentos.}

Após a sanção da LDBEN de 1996, o Regime de Colaboração foi abordado na Lei $n^{\circ}$ 10.172, de 9 de janeiro de 2001, que criou o Plano Nacional de Educação, PNE, vigente entre os anos de 2001 e 2011 . No texto da Lei $n^{\circ} 10.172 / 2001$, novamente, não há uma definição do Regime de Colaboração, mas sim um reforço à necessidade de políticas públicas em conformidade com esse regime. Porém, o documento anexo à Lei $\mathrm{n}^{\mathrm{o}}$ 10.172/2001 esclarece que o Regime de Colaboração também deve ser estabelecido entre entes federados de mesma esfera administrativa, não sendo uma particularidade entre a União e os municípios. Nesse sentido, a Lei $\mathrm{n}^{\mathrm{o}}$ 10.172/2001 corrobora com o sentido de Regime de Colaboração utilizado no artigo 62 da LDBEN de 1996.

A Lei 10.172/2001 traz em seu texto a expressão "aprimoramento contínuo do Regime de Colaboração" (BRASIL, 2001, Anexo da Lei n 10.172/01, p. 01), reforçando a necessidade dessa ação, não só para o financiamento, mas para a plena consolidação da divisão das responsabilidades educacionais:

Para que a gestão seja eficiente há que se promover o autêntico federalismo em matéria educacional, a partir da divisão de responsabilidades previstas na Carta Magna. A educação é um todo integrado, de sorte que o que ocorre num determinado nível repercute nos demais, tanto no que se refere aos aspectos quantitativos como qualitativos. Há competências concorrentes, 
como é o caso do ensino fundamental, provido por Estados e Municípios. Ainda que consolidadas as redes de acordo com a vontade política e capacidade de financiamento de cada ente, algumas ações devem envolver Estados e Municípios, como é o caso do transporte escolar. Mesmo na hipótese de competência bem definida, como a educação infantil, que é de responsabilidade dos Municípios, não pode ser negligenciada a função supletiva dos Estados (art. 30,VI,CF) e da União (art. 30. VI, CF e art. $211, \S 1^{\circ}, \mathrm{CF}$ ). Portanto, uma diretriz importante é o aprimoramento contínuo do regime de colaboração. Este deve dar-se, não só entre União, Estados e Municípios, mas também, sempre que possível, entre entes da mesma esfera federativa, mediante ações, fóruns e planejamento interestaduais, regionais e intermunicipais. (BRASIL, 2001, Anexo da Lei $\mathrm{n}^{\mathrm{o}} 10.172 / 01$, p. 01$)$.

Dentro da vigência do Plano Nacional de Educação da Lei no ${ }^{\circ} 10.172$, de 2001, o Decreto $\mathrm{n}^{\mathrm{o}}$ 6.094, de 24 de abril de 2007, também reforçou a necessidade e promoveu avanços no sentido da implementação do Regime de Colaboração. Por meio deste Decreto, foi legitimado o Plano de Desenvolvimento da Educação (PDE) e criado o Plano de Metas e Compromisso Todos pela Educação (PMCTE), conjuntamente com o Plano de Ações Articuladas (PAR), pelos quais o governo federal buscava, entre outras coisas, orientar as gestões educacionais dos governos dos entes federados, municípios e estados, para promoverem ações conjuntas, em regime de colaboração, buscando a melhoria da qualidade da educação. Analisando somente questões relacionadas ao Regime de Colaboração, fica evidente no Decreto ${ }^{\circ} 6.094$ que, para a plena execução do Regime de Colaboração, não há somente a necessidade de fundos de financiamento educacional e de fundos de redistribuição de recursos para a educação, mas sim do engajamento em cooperação dos governos subnacionais e nacional nas políticas educacionais.

No mesmo Decreto n ${ }^{0}$ 6.094, o Governo Federal criou o Plano de Ações Articuladas (PAR), que visava à plena implementação de políticas educacionais em Regime de Colaboração. Porém, esse decreto não norteou nem esclareceu como o regime seria executado. Esse documento da União salienta a necessidade da realização de políticas educacionais em que os entes federados estejam engajados conjuntamente, não somente na questão financeira, mas também em toda a estrutura administrativa da educação. 
Na tentativa de consolidar o Regime de Colaboração por meio do PAR, a União dava auxílio aos entes federados, principalmente aos municípios, para a sua elaboração e fiscalizava a execução do Plano. O PAR fez parte do Plano de Metas e Compromisso Todos pela Educação (PMCTE), que visava ser um instrumento para melhoria da educação pela participação dos gestores das escolas, das famílias, da comunidade e de representantes dos governos subnacionais e nacional.

Com a sanção do PNE de 2001, o entendimento sobre o Regime de Colaboração apresentou mais relevância e novos modelos de pactos e acordos, que fogem da questão do financiamento e da formação do profissional do magistério, foram elaborados.

Em cumprimento ao Artigo 214 da Constituição Federal de 1988, reformulado em 2006, foi sancionada em 2014 a Lei $n^{\circ}$ 13.005, que estabeleceu o Plano Nacional de Educação (PNE). Essa lei enfatiza a necessidade de fortalecimento e plena implantação do Regime de Colaboração, e deixa claro que o regime não se restringe ao financiamento e às questões redistributivas.

O artigo sétimo da Lei $\mathrm{n}^{\mathrm{o}}$ 13.005/2014 apresenta que devem ser implementadas ações em conjunto entre os entes federados, visando o engajamento para alcance das metas do PNE. O parágrafo quarto nesse artigo evidencia que o Regime de Colaboração terá modalidades diferentes, demonstrando maior amplitude do que somente a questão financeira, enquanto o parágrafo sétimo deixa claro que o Regime de Colaboração deve ser entendido como a adoção de arranjos de cooperação entre os entes federados que visem à melhoria da educação. Os municípios poderão inclusive usar de Arranjos de Desenvolvimento Educacional para o fortalecimento do regime:

Art. $7^{\circ}$ A União, os Estados, o Distrito Federal e os Municípios atuarão em regime de colaboração, visando ao alcance das metas e à implementação das estratégias objeto deste Plano.

$\S 1^{\circ}$ Caberá aos gestores federais, estaduais, municipais e do Distrito Federal a adoção das medidas governamentais necessárias ao alcance das metas previstas neste PNE.

$\S 2^{\circ}$ As estratégias definidas no Anexo desta Lei não elidem a adoção de medidas adicionais em âmbito local ou de instrumentos jurídicos que 
formalizem a cooperação entre os entes federados, podendo ser complementadas por mecanismos nacionais e locais de coordenação e colaboração recíproca.

$\S 3^{\circ}$ Os sistemas de ensino dos Estados, do Distrito Federal e dos Municípios criarão mecanismos para o acompanhamento local da consecução das metas deste PNE e dos planos previstos no art. 8o.

$\S 4^{\circ}$ Haverá regime de colaboração específico para a implementação de modalidades de educação escolar que necessitem considerar territórios étnico-educacionais e a utilização de estratégias que levem em conta as identidades e especificidades socioculturais e linguísticas de cada comunidade envolvida, assegurada a consulta prévia e informada a essa comunidade.

$\S 5^{\circ}$ Será criada uma instância permanente de negociação e cooperação entre a União, os Estados, o Distrito Federal e os Municípios.

$\S 6^{\circ} \mathrm{O}$ fortalecimento do regime de colaboração entre os Estados e respectivos Municípios incluirá a instituição de instâncias permanentes de negociação, cooperação e pactuação em cada Estado.

$\S 7^{\circ} \mathrm{O}$ fortalecimento do regime de colaboração entre os Municípios darse-á, inclusive, mediante a adoção de arranjos de desenvolvimento da educação. (BRASIL, 2014, p. 01).

Sobre os parágrafos $4^{\circ}, 5^{\circ}, 6^{\circ}$ e $7^{\circ}$ do artigo $7^{\circ}$ da Lei $n^{\circ} 13.005$ de 2014, Cury (2014) destaca os elementos fortes existentes neles, e que são princípios para se compreender melhor a dinâmica de Consolidação do Regime de Colaboração. Ao nortear o Regime de Colaboração, esses parágrafos são:

uma novidade nesta trajetória já longa de busca de um regime de colaboração. As palavras são fortes dentro da ciência política: negociação, cooperação e pactuação. Todas elas se voltam para a articulação interfederativa por cujas mesas deverá escoar a implementação das políticas educacionais. (CURY, 2014, p. 1064)

De todas as legislações sancionadas desde a promulgação da Constituição de 1988, a Lei $\mathrm{n}^{\circ} 13.005$ de 2014 foi a que mais ressaltou o Regime de Colaboração, tendo o maior número de citações do Regime de Colaboração em seu texto. Além das diversas citações do Regime de Colaboração, ela possui um longo artigo que tenta lançar luz aos entes federados na busca de políticas em Regime de Colaboração. Assim, vê-se que o Regime de 
Colaboração presente na Constituição de 1988 não foi esquecido, e as legislações federais buscam uma maneira de implementá-lo, inserindo mais clareza sobre como implementar o Regime de Colaboração.

\section{Para onde apontam os documentos?}

Analisando as legislações que tratam do Regime de Colaboração entre os anos de 1988 e 2020, vê-se uma evolução de sua interpretação pelo avanço da presença dentro das legislações ao longo destes anos. Este avanço na presença do termo Regime de Colaboração nas legislações mostra o interesse na plena implementação do Artigo 211 da Constituição Federal de 1988, o qual deixa claro que o Regime de Colaboração não se restringe somente a questões de financiamento da educação. Tal avanço que pode ser contabilizado pelo aumento no número de citações do termo Regime de Colaboração dentro das legislações. Na LDBEN 9394/1996 há quatro citações do termo Regime de Colaboração em todo documento, enquanto no PNE de 2014, Lei n 13.005/2014, já há 21 citações, contando a Lei e o Anexo.

De 1988 a 1996, o Regime de Colaboração ficou basicamente sendo aplicado no sentido do financiamento educacional através de fundos de redistribuição de recursos, como o Fundo Nacional de Desenvolvimento da Educação, FNDE. Com a sanção da LDBEN de 1996, o regime de colaboração foi trazido para a interpretação que a Constituição de 1988 deu a ele, um regime para elaboração de políticas educacionais entre os entes federados que não se restrinja a questões de financiamento educacional. O avanço que a LDBEN de 1996 trouxe para o Regime de Colaboração está em apontar que os entes federados devem promover parcerias para promover a formação e a capacitação dos professores. As legislações posteriores continuaram promovendo o regime de colaboração para todos os tipos de parcerias entre os entes federados, inclusive para parcerias horizontais, a exemplo: município com município, e não se restringir a parcerias verticais, estado com municípios.

Conforme afirma Candido (2019) ao analisar artigos sobre o Regime de Colaboração publicados entre os anos de 1996 e 2014, as interpretações apresentadas nos artigos acadêmicos mostram que o regime de colaboração não se restringe somente aos aspectos financeiros, nem mesmo às políticas horizontais de colaboração, políticas pelas 
quais o Governo Federal auxilia os governos estaduais e municipais, ou um governo estadual auxilia os governos municipais.

Candido (2019) coloca um regime de colaboração mais amplo e abrangente, no qual as relações de colaboração se dão entre todos os entes federados tanto na forma horizontal, por exemplo: parcerias entre municípios e parcerias entre estados, quanto de forma vertical: parcerias entre um município e um estado, parceria entre um estado e o governo federal, entre outras. Estas parcerias podem ser específicas, um município pode ter parcerias diferentes com municípios diferentes, não havendo necessidade de uma homogeneidade nas parcerias horizontais. Um município pode ter um modelo de parceria com determinado município e outro modelo de parceria, com outro objeto, com um município diferente. As parcerias horizontais são acordos bilaterais que busquem uma melhor oferta de educação em ambos os municípios.

Um ponto importante dentro do regime de colaboração é a total autonomia dos entes federados, permitindo que os municípios celebrem parcerias com quaisquer outros municípios. Não há necessidade que os municípios sejam limítrofes, ou que estejam no mesmo Estado, para haver parcerias em Regime de Colaboração. Estas parcerias podem resolver problemas gerados na gestão da educação de cidades próximas, até mesmo se estiverem em Estados diferentes, pois seus sistemas de educação pertencem a secretarias de educação e sistemas de financiamentos diferentes. Muitas vezes, estas escolas ficam sujeitas aos fluxos migratórios regionais e à oferta de trabalho que acaba fazendo os pais morarem em um estado e matricularem seus filhos em uma cidade próxima, em outro estado, pois é onde trabalham durante um determinado período do ano. Nestes casos, além dos problemas de financiamento da educação, existem questões de currículo que podem ser ajustadas com um acordo em regime de colaboração, buscando uma educação mais homogenia na região.

A Constituição de 1988 permite acordos em regime de colaboração entre um município e um estado diferente do estado daquele município, não havendo nenhuma ressalva. Porém, este tipo de acordo pode gerar desconforto políticos para gestores e futuros candidatos devido aos arranjos político-partidários existentes no Brasil. Mesmo assim, existem parcerias entre uma escola, ou prefeitura, de um determinado estado, com 
universidades de outros estados. As experiências de ensino remoto mostram como estes acordos podem ser executados na prática, não necessitando de deslocamentos, ofertando melhorias na formação dos discentes e outras formas de parcerias técnicas.

Quando escolas e universidades realizam parcerias não estão celebrando políticas em regime de colaboração, mas podem celebrar acordos benéficos para ambos, burlando o sistema burocrático da administração pública e ofertando uma melhor educação pública. Nesse sentido, o incentivo para parcerias bilaterais não pode depender somente da boa-fé da gestão pública, que muitas vezes se prende aos arranjos político-partidários, mas do interesse e do conhecimento do Regime de Colaboração pelas próprias instituições de ensino. São as instituições de ensino que devem trazer luz aos gestores públicos sobre o que são políticas educacionais em Regime de Colaboração e como os entes federados podem celebrar tais acordos. Por isto, conhecer o Regime de Colaboração, na Constituição de 1988 e nas posteriores legislações educacionais, é de grande importância para professores e gestores de todas as instituições de ensino.

\section{Considerações Finais}

O Regime de Colaboração é um termo presente na Constituição Federal de 1988 e nas legislações educacionais apresentadas, tendo sua compreensão regulamentada à medida em as demandas sociopolíticas se interpõem. Tal estratégia deve ser entendida como uma obrigação constitucional, acima dos conchavos e da disputa eleitoral e partidária, firmandose como uma política contínua entre os entes federados, cujo objetivo pauta-se na organização do sistema público brasileiro, no sentido de ofertar uma educação de qualidade dentro do território nacional, permitindo maior integração e dirimindo possíveis divergências.

Portanto, sua materialização além de rever os papéis de cada ente federado, com destaque para a União em seu caráter redistributivo e suplementar, visa um investimento mais igualitário dos recursos dada a multiplicidade de cenários encontrados no chão das escolas públicas brasileiras. Tal condição fortalece o direito à educação, garantindo um 
padrão de qualidade, conforme preconiza o art.206, inciso VII, da Constituição.

Assim, a corresponsabilidade e o compartilhamento de metas, índices e estratégias mediante a celebração dos acordos apontam para uma ação articulada entre União, Estados e Municípios onde cada um tem autonomia, mas também responsabilidades bem definidas, ensejando um planejamento cooperativos entre os entes, a exemplo da elaboração e execução dos respectivos Planos Nacional, Estadual e Municipal de Educação, para além de outras políticas educacionais.

O maior desafio talvez seja encontrar um ponto de equilíbrio entre o que reza a lei e as práticas executadas de maneira a que os acordos venham ser celebrados de forma duradoura, para se estendam além das alterações nas legislações educacionais e das trocas de gestão, naturais do processo democrático, mantendo a perenidade necessária para que a curto, médio e longo prazos as mudanças ocorram sendo entendido como uma política de estado, e não de governos.

\section{Referências}

ABRUCIO, F. L. A dinâmica federativa da educação brasileira: diagnóstico e propostas de aperfeiçoamento. In: OLIVEIRA, R. P. ; SANTANA, W. (Org.). Educação e federalismo no Brasil: combater as desigualdades, garantir a diversidade. Brasília: UNESCO, 2010. p. 39-70.

BRASIL. Constituição da República Federativa do Brasil. 1988. Disponível em: http://www.planalto.gov.br/ccivil_03/constituição/constituição88.htm . Acesso em: 17.05.2018.

BRASIL. Lei nº394/1996 - Lei de Diretrizes e Bases da Educação (LDBEN/1996). 20 de dezembro de 1996. Disponível em: http://www.planalto.gov.br/ccivil_03/LEIS/L9394.htm. Acesso em: 17.05.2018. Acesso em: 17.05.2018.

BRASIL. Plano Nacional de Educação 2001-2010 : Lei $\mathbf{n}^{0}$ 10.172, de 09 de janeiro de 2001, que aprova o Plano Nacional de Educação (PNE) e dá outras providências, 2001.Disponível em: http://www.planalto.gov.br/ccivil_03/leis/leis_2001/110172.htm . Acesso em: 17.12.2018.

BRASIL. Emenda Constitucional número 53. 19 de dezembro de 2006. Disponível em: http://www.planalto.gov.br/cCivil_03/Constituição/Emendas/Emc/emc53.htm. Acesso em: 
17.05.2019.

BRASIL. Plano Nacional de Educação 2014-2024 : Lei no 13.005, de 25 de junho de 2014, que aprova o Plano Nacional de Educação (PNE) e dá outras providências. - Brasília : Câmara dos Deputados, Edições Câmara, 2014.

BRASILIA. Conselho Municipal e suas articulações com as políticas públicas. Brasília: Ministério da Educação, Secretaria da Educação Básica; Universidade Federal de Santa Catarina, 2019.

CANDIDO, Renato Alexandre Oliveira. Regime de colaboração: um recorte temporal dos artigos publicados na plataforma periódicos Capes (1996-2014). 2019. 147 p. Dissertação (mestrado) - Universidade Estadual de Campinas, Faculdade de Educação, Campinas, SP.

CURY, Carlos Roberto Jamil. A qualidade da educação brasileira como direito. Educação e Sociedade, vol.35, n.129, pp.1053-1066, 2014.

WERLE, F. O. C. A reinvenção da gestão dos sistemas de ensino: uma discussão do Plano de Desenvolvimento da Educação 2007. Revista Educação em Questão, Natal, v. 35, n. 21, p. 98-119, maio/ago. 2009.

Enviado em: 07/07/2021

Revisado em: 16/09/2021

Aceito em: 04/11/2021 